\title{
Teaching online: foundational concepts of online learning and practical guidelines
}

\author{
Hye Chang Rhim ${ }^{1}$ and Heeyoung Han $^{2}$
}

${ }^{1}$ Harvard University T.H Chan School of Public Health, Boston, MA, and ${ }^{2}$ Department of Medical Education, Southern Illinois University School of Medicine, Springfield, IL, USA

Medical schools have been slowly adopting online learning into pedagogical methods for more than a decade. While some medical educators are reluctant to accept these changes, the ongoing coronavirus disease 2019 (COVID-19) pandemic poses a threat to the delivery of traditional medical education, which has accelerated the inevitable implementation of online learning. This sudden change may be a new challenge to medical educators who are new to this territory. Therefore, this review aims to provide foundational concepts of online learning and practical guidelines in the context of medical education. The authors first identify three foundational concepts, which are transactional distance, presence, and independent learners. In online learning, transactional distance, determined by dialogue and structure, becomes more important than physical distance. Furthermore, effective and successful online learning requires the achievement and accommodation of cognitive, social, and teaching presences. It is also crucial to recognize learners not as passive recipients of information predefined by a teacher, but as active, capable, and independent individuals. The authors, then, discuss the practical guidelines for designing an effective online curriculum. Five online pedagogical guidelines are laid out in this review: design structures and flows to embrace experiential learning, accommodate both synchronous and asynchronous learning, design/facilitate interactions, promote practice opportunities, and promote a learning community. By understanding the foundational concepts and applying these guidelines, the adoption of online learning in the medical school may supplement the traditional medical education or even provide additional benefits in the new normal after the COVID-19 pandemic.

Key Words: Online learning, Distance education, Transactional distance, Experiential learning, Presence, Independent learners

\section{Introduction}

The coronavirus disease 2019 (COVID-19) outbreak has presented a unique challenge to healthcare systems around the world including the delivery of medical education. Social distancing precluded medical students from gathering for lectures and participating in clinical rotations. Medical educators soon adapted to this crisis by transitioning their curricula into an online format. Although the COVID-19 pandemic has disrupted medical education in unprecedented ways, ironically, the virus seemed to have worked as the catalyst for embracing virtual learning [1]. In fact, prior to the COVID-19 pandemic, medical schools have been slowly implementing online learning into pedagogical methods for more than a decade [2,3]; however, they have been still reluctant to accept these changes [1]. Despite the
Received: July 15, 2020 • Revised: July 15, 2020 • Accepted: July 23, 2020 Corresponding Author: Heeyoung Han (https://orcid.org/0000-0002-7286-2473) Department of Medical Education, Southern Illinois University School of Medicine, 913 North Rutledge Street, PO Box 196, Springfield, IL 62794-9638, USA

Tel: +1.217.545.8536 Fax: +1.217.545.0120 email: hhan@siumed.edu
Korean J Med Educ 2020 Sep; 32(3): 175-183.

https://doi.org/10.3946/kjme.2020.171

eISSN: 2005-7288

(C) The Korean Society of Medical Education. All rights reserved. This is an open-access article distributed under the terms of the Creative Commons Attribution Non-Commercial License (http:// creativecommons.org/licenses/by-nc/3.0/), which permits unrestricted non-commercial use, distribution, and reproduction in any medium. provided the original work is properly cited. 
uncertainty regarding how long this pandemic will persist and the possibility of a new pandemic in the future, the pedagogical reevaluation of online learning as the main curriculum environment is undergoing in medical education [4].

However, this transition requires more than simply recording a lecture and uploading it in online platforms. It is not a simple copy and paste practice of existing face-to-face teaching activities in an online format. It is a re-mediation process of the current instructional practices, requiring to revisit the current assumptions on physical space and time in educational practices $[5,6]$. The COVID-19 pandemic was unexpected and the changes necessary to continue medical educations were abrupt; thus, the adoption of online learning may be challenging to medical educators, in particular, who are new to this territory. Therefore, the purpose of this review is to provide foundational concepts of online learning that can be historically traced back to distance education and discuss the practical guidelines for designing an effective online curriculum.

\section{Foundational concepts behind online learning}

Online learning has a historical root in distance education; the latter was an alternative educational practice and program for nontraditional learners who could not have had education opportunities otherwise [7]. Online learning is described as access to learning experiences via the use of the Internet and considered a more recent version of distance learning [8]. Although there seem to be subtle differences in the definitions of e-learning, online learning, and distance learning, these terms are used interchangeably and rooted in distance education [8]. The physical and temporal distance was emphasized in shaping this new form of education 2 centuries ago. The development of the postal system provided opportunities for non-traditional students who worked during the day and lived distant from a college. Distance education enabled these students to overcome distance and time, and the subsequent advent of newer technologies such as TV and the Internet closed the distance between teachers and students even more. While the current stage of technological innovations allows for faster and easier synchronous and asynchronous communications, transactional distance still needs to be considered in online learning.

There are three foundational concepts for effective distance education programs, which become the basis of instructional design of online learning and teaching practices: Transactional distance, Presence, and Independent learners.

\section{Transactional distance}

Physical distance is a barrier to traditional education. However, distance in online learning is not defined by physical distance but "transactional distance" [9]. According to Moore [10], transactional distance is a social, psychological, and relational distance between teachers and learners that is fluid and manageable based on a function of dialogue and structure. When dialogues, meaningful interactions between teachers and learners for the creation of knowledge, are increased, the transactional distance between them can be reduced. Even in a classroom, if a teacher does not have a dialogue with students, the latter would feel a greater transactional distance.

The degrees and characteristics of dialogues depend on numerous factors but mainly on the structure of the course and, to a lesser extent, on the medium of communication. Here, structure indicates the rigidity or flexibility of the educational program. It depicts the 
degree to which a course can respond to each learner's different demands and preferences. When the teaching is highly structured without consideration for the learners' differences and individualization in their learning processes with minimal dialogue, the transactional distance becomes high [10]. Online courses not providing ongoing dialogue between a teacher and learners and rarely accommodating individual students' needs would have high transactional distance and become undesirable. Therefore, educators need to understand that the medium of communication would not automatically close the distance between teachers and students. Furthermore, the transactional distance may remain intact depending on the extent of dialogue and structure.

\section{Cognitive, social, and teaching presences}

Another foundational concept of online education is presence. There are three kinds of presence: cognitive presence, social presence, and teaching presence [11]. When an individual is involved in online learning, it implies that the individual becomes a member of a "community of inquiry" as a learner or a teacher (or both). Effective and successful online learning requires each member to achieve and accommodate these three types of presence [12].

"Cognitive presence" indicates the degree to which the learners can construct meaning through constant $\mathrm{ex}^{-}$ changes of thoughts questioning, answering, brainstorming, discussing, and solving a problem [11,12]. In the setting of an online learning environment, it is worth considering how the learners can maximize this cognitive presence because its extent can vary depending on the communication medium. A video lecture, for example, would give students a sense of what message the teacher tried to convey. However, the teacher would not possibly know what the students think about the topic. In this case, the students' cognitive presence is lacking.

"Social presence" can be achieved when learners project their personal feelings, emotions, questions, and characteristics into the community [11,12]. Garrison et al. [12] argued that socio-emotional interactions and support are crucial and essential at times in nurturing cognitive presence and, therefore, leading to meaningful educational outcomes [11]. Social presence helps members in the community reduce psychosocial tension and uncertainty as well as encourages the group to freely discuss and collaborate on a project, exceeding simple interactions and one-way instructions. Collaborations draw learners to a shared experience space to construct and confirm meaning. In this respect, a successful online learning community needs to promote collaboration rather than simply exist as a place to download information.

“Teaching presence" indicates two general functions, design of the educational experiences and facilitation [11,12]. The former function may be the primary responsibility of the teacher who selects, organizes, presents course content, and develops learning activities and assessments, providing clear expectations and a basic guideline on learning activities. Facilitation can be achieved by the teacher or the students in an online environment. The role of teaching presence is to support and enrich social as well as cognitive presence to accomplish meaningful educational outcomes.

\section{Independent learners}

Effective online teaching requires a fundamental perspective change regarding learners. Learners are not passive recipients of information predefined by a teacher, but active, capable, and independent individuals with their own learning processes to explore their environments in knowledge construction [9]. As briefly discussed in the previous section of teaching presence, 
teachers' roles lean toward the facilitation and the design of learning experiences that allow learner autonomy. However, it is also true that students have varying degrees of ability to develop a personal learning strategy, to find resources for study, and to assess their own progress [10]. A higher transactional distance means that teaching requires more autonomous learners; however, students do not always have a high level of autonomy. The role of teachers in the online environment, then, includes not only providing information but also motivating and empowering students to enrich their learning experience.

In sum, teaching online requires three foundational understandings about distance, presence, and learners. Transactional distance, cognitive presence, social presence, teaching presence, and independent learners can become guiding parameters in the design of online learning programs. In the following section, we will discuss practical guidelines for online teaching that are based on those three foundational concepts.

\section{Practical guidelines for online teaching}

Online teaching is a design of learning experiences and facilitation of those experiences. In this section, we will discuss the design of learning experiences by explaining five online pedagogical guidelines: design structure and flow to embrace experiential learning, accommodate both synchronous and asynchronous learning, design/ facilitate interactions, promote practice opportunities, and promote a learning community.

\section{Design structure and flow to embrace experiential learning}

Effective online teaching can be achieved by embracing an experiential learning approach [13].
Experiential learning explains an individual' s learning process as a knowledge creation cycle, where learners reflexively progress through the cycle of concrete experiences, reflective observation, identification of general principles, and practically applying what they learned for further experiences. In the context of medical education, learning from experience may conjure up an image of medical students observing and learning from patients during clinical rotations. However, it may extend to small group discussions, team-based learning, cadaver dissection lab during the preclinical years, and even their personal experiences before medical training. A teacher's instruction or lecture can be considered as a stimulus that provides the learner with an opportunity to observe what a content expert thinks and knows [14]. Students absorb what they have been told as a response and ought to have opportunities to connect their experiences with their observations to identify general principles $[14,15]$. Students need to actively engage and interact with their surroundings to test what they learned, that is, students are allowed to experience further to absorb (response) given instruction (stimulus). Therefore, online teaching is not one single event of lecturing but continuous facilitation of the experiential learning cycle.

The flipped classroom is a pedagogical approach that allows an experiential learning cycle in an online learning environment. In a flipped classroom, students learn didactic materials at their own pace before the class using pre-recorded lectures available asynchronously. Students would connect their prior experiences with the newly observed resources to create their own knowledge. Then, students would bring their understandings during face-to-face or synchronous online interactions with the teacher, where they can actively test their understandings and engage in problem-solving while interacting with the teacher and peers [15]. With 
the expert's scaffolding and guidance on the side, learners can further develop their own knowledge and skills that would feed into future experiences [16].

\section{Accommodate both synchronous and asynchronous learning}

Online learning has two technologically different processes based on the timeliness of interactivity, which should be considered in the design of learning experiences. One is synchronous online experiences where all participants have real-time interactions either in a text-based or video-based environment. Learning activities in a chatting room or video conferencing is an example of a synchronous online experience. Asynchronous online experiences occur when participants' interactions continue with time delays such as online discussions in a learning management system.

As both modes of online interactivity have pros and cons regarding learning experiences, it is important to accommodate these two online learning activities for appropriate purposes [17]. A synchronous online activity often has a limited timeframe and would leave the audience little time to reflect on. For example, live lectures in the medical education curriculum focusing on complex clinical or basic science topics can be provided as recorded lectures so that learners have better control of their pace and learning processes. In addition, providing a supplementary asynchronous online discussion forum would be helpful to overcome the lack of dialogue as students and teachers can share ideas without time constraints and have enough time to reflect and elaborate their thoughts on complex topics. Synchronous online interactions, however, can be effective in discussing topics with some preparation work, creating social presence among members as well as planning tasks that need real-time feedback.

\section{Design and facilitate interactions}

There are four interactions that online teachers should consider: students' interaction with resources, interaction with the instructor, interaction with the peer, and interaction with self $[18,19]$. These interactions have been found crucial for meaningful learning experiences and effectiveness in online learning [20]. Facilitating interaction with resources can be found in the instructional design of learning materials. A teacher would spend significant time and effort to develop well-organized lecture materials with a clear overview, an appropriate depth in synthesizing each topic, and a summary. Students' interaction with the instructor and the peer is crucial for creating mutual cognitive and social presence; it can be facilitated synchronously as well as asynchronously via different activities. For example, a teacher providing individual feedback on students' questions or performance. A small group discussion or an online forum where students and teachers can post questions and freely share their thoughts can be an efficient way to facilitate those interactions. Students' interaction with self facilitates a metacognitive process where students can set up learning goals and monitor their progress. An online teaching process can incorporate these students' reflection activity as a routine to promote the students' habitual independent learning.

\section{Promote practice opportunities}

Online learning may be seen as an alternative instructional modality just for classroom learning without actual practices or experiences. As discussed in the earlier section, however, concrete experience is a crucial part of any learning process. This becomes more critical in medical education where clinical experience is the central part of medical competency development. 
Despite the physical distance, there are ways that medial educators can facilitate learners to have clinical practices in an online environment. One is a mediated experience. First of all, it is critical to differentiate between what can be mediated and what cannot be. For example, teaching students about working on a night shift and interacting with different healthcare professionals might be hard to mediate in an online environment. However, some experiences can be practiced in an online environment. For example, Klamen [21] argued that third-year medical students cannot possibly see all kinds of patients in clerkship rotations [22]. Even after seeing the patient, practicing clinical reasoning in which students identify differential diagnoses and treatment plans did not occur due to busy workflow in hospitals and clinics [23]. Moreover, it is also challenging for novice medical learners to observe attending physicians' thought processes on a busy clinic day. After recognizing this issue, Klamen et al. [21] developed an online video-based critical clinical competency curriculum where medical students practice clinical reasoning deliberately with 144 distinct patient cases. In this curriculum, the process of students' practicing clinical reasoning was designed in a way that medical learners stopped to think through each new piece of patient information. In this way, they can rule in and out their differential diagnoses as explaining their justifications. After practicing their own clinical reasoning, the students can watch how expert panels consisting of different specialties reason through to compare their reasoning with those of the experts. The curriculum is available online (https://www.siumed.edu/oec/ccc) for free to any medical learners. Another example is found in a recent report of Hofmann et al. [24], where medical students engaged in virtual rounds with COVID-19 patients using a HIPAA (Health Insurance and Portability and Accountability Act) compliant video- conferencing tool. They have discussed if virtual rounds can be utilized especially for clinical experiences excluding medical students due to safety or difficult patient cases. These examples represent experiences online learning environments can provide to medical learners, which are almost impossible to gain otherwise.

\section{Facilitate a learning community}

Adopting online learning means transforming teaching philosophy to embracing organic collective intelligence for a sustainable learning environment [5]. In online learning, teachers are not the only source for building knowledge; students learn from teaching others, and by observing their peer students. The line between the teacher (knowledge provider) and the learner (knowledge receiver) is blurred in online learning. Effective online learning can be sustainable and strengthened by a learning community [25]. There must be a sense of a learning community at a medical school. Teachers can simply recognize and facilitate the existing learning community as well as create a new one even beyond the existing school system.

A sense of a learning community can be created by asynchronous interactions as well as synchronous interactions online or in-person. A teacher's asynchronous online presence at an online discussion forum can be beneficial because of the students' extended opportunity to interact with the teacher anytime anywhere. Teachers take multiple roles in facilitating a learning community: an information provider, a facilitator for students' participation, collaboration and peer learning, a curator to connect students to other organized resources, and a lifelong learner, not just an evaluator. Social presence is crucial in creating a functional online learning community [26]. Members including teachers should feel comfortable being who they are and be able to share struggles as well as 
emotions. This social atmosphere becomes fundamental for members' higher-order thinking processes in their learning process. The teachers' efforts to get to know individual students, non-judgmental attitude about the students' lack of knowledge, and vulnerability to reveal their own learning needs can help create and facilitate a learning community in online learning.

\section{Discussion}

Although the COVID-19 pandemic poses a threat to traditional medical education, it has also provided an opportunity to recognize online learning as an effective pedagogical method. Its effectiveness, however, depends on the degree to which medical educators are aware of the foundational concepts of online learning. Unlike a physical distance that was a barrier to traditional education, transactional distance should be considered in online education. The educators need to understand that the advancement in communication technology itself would not automatically close the distance between the teachers and students; instead, educators should try to promote dialogue and social presence as well as minimize structure in order to reduce the transactional distance. Also, the role of a teacher is not limited to someone who provides information but also someone who motivates students to enrich their learning experience.

We provided five online pedagogical guidelines for designing curriculum in the medical education context. The flipped classroom is one of the methods to embrace experiential learning. Both synchronous and asynchronous learning should be properly balanced to create a social presence as well as provide time for reflection. Just like office hours and small group discussion sessions in the traditional education setting, the online environment can also have forums that facilitate interactions among peers and instructors. Practice opportunities can be more widely available through online platforms in certain patient cases. Lastly, efforts need to be made to maintain a sense of a learning community even in an online environment.

By understanding the foundational concepts and applying the online pedagogical guidelines (which are summarized in Fig. 1), the adoption of online learning in

Fig. 1. The Summary of the Foundational Concepts and Practical Guidelines for Online Teaching and Learning
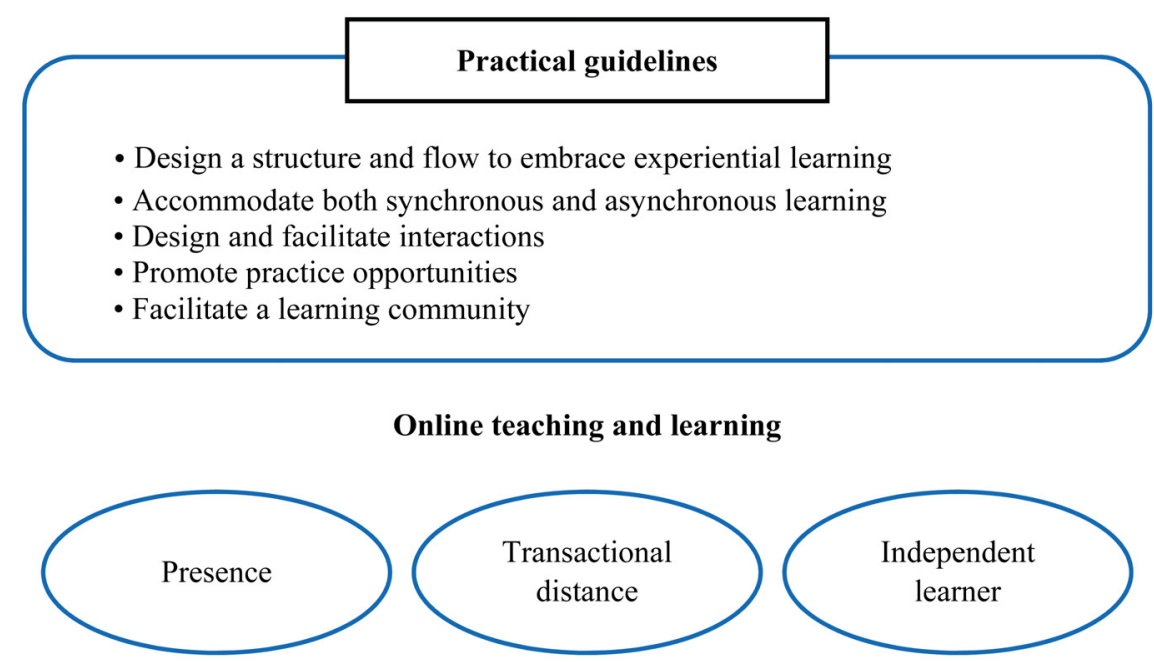

Foundational concepts 
the medical school may supplement traditional medical education or even provide additional benefits in the new normal after the COVID-19 pandemic.

\section{ORCID:}

Hye Chang Rhim: https://orcid.org/0000-0002-7986-6493

Heeyoung Han: https://orcid.org/0000-0002-7286-2473

Acknowledgements: None.

Funding: No funding was obtained for this study.

Conflicts of interest: No potential conflict of interest relevant to this article was reported.

Author contributions: HCR and $\mathrm{HH}$ equally contributed to conception or design of the work, data collection, data analysis and interpretation, drafting the article, critical revision of the article, and final approval of the version to be published.

\section{References}

1. Woolliscroft JO. Innovation in response to the COVID-19 pandemic crisis. Acad Med. 2020;95(8): 1140-1142.

2. Rose S. Medical student education in the time of COVID-19. JAMA. 2020 Mar 31 [Epub]. https://doi.org/ 10.1001/jama.2020.5227.

3. Hew KF, Lo CK. Flipped classroom improves student learning in health professions education: a meta-analysis. BMC Med Educ. 2018;18(1):38.

4. Emanuel EJ. The inevitable reimagining of medical education. JAMA. 2020 Feb 27 [Epub]. https://doi.org/ 10.1001/jama.2020.1227.

5. Han H. Mediation and remediation in online learning. Int J Learn. 2007;14(2):225-230.

6. Bauman Z. Liquid modernity. Malden, USA: Blackwell Publishers Inc.; 2000.
7. Wedemeyer CA. Learning at the back door: reflections on non-traditional learning in the lifespan. Madison, USA: The University of Wisconsin Press; 1981.

8. Moore JL, Dickson-Deane C, Galyen K. e-Learning, online learning, and distance learning environments: are they the same? Internet High Educ. 201 1;14(2):129-135.

9. Moore MG. Theory of transactional distance. In: Keegan D, ed. Theoretical Principles of Distance Education. London: Routledge; 1997:22-38.

10. Moore MG. Theory of transactional distance. In: Keegan D, ed. Theoretical Principles of Distance Education. London, UK: Routledge; 1993;22-38.

11. Anderson T. Teaching in an online learning context. In: Anderson T, ed. The Theory and Practice of Online Learning. 2nd ed. Edmonton, Canada: AU Press; 2008:343-366.

12. Garrison DR, Anderson T, Archer W. Critical inquiry in a text-based environment: computer conferencing in higher education. Internet High Educ. 1999;2(2-3): 87-105.

13. Yardley S, Teunissen PW, Dornan T. Experiential learning: AMEE guide no. 63. Med Teach. 2012; 34(2):el02-el 15.

14. Dewey J. The reflex arc concept in psychology. Psychol Rev. 1896;3(4):357-370.

15. Hurtubise L, Hall E, Sheridan L, Han H. The flipped classroom in medical education: engaging students to build competency. J Med Educ Curric Dev. 2015;2: 35-43.

16. Vygotsky LS. Mind in society: the development of higher psychological processes. Cambridge, USA: Harvard University Press; 1980.

17. Hrastinski S. Asynchronous and synchronous e-learning. Educ Q. 2008;31(4):51-55.

18. Hirumi A. A framework for analyzing, designing, and sequencing planned elearning interactions. In: Orellana A, Hudgins T, Simonson M, eds. The Perfect Online 
Course: The Best Practices for Designing and Teaching. Charlotte, USA: Information Age Publishing; 2009: 201-228.

19. Moore MG. Three types of interaction. Am J Distance Educ. 1989;3(2):1-7.

20. Swan K. Building learning communities in online courses: the importance of interaction. Educ Commun Inf. 2002;2(1):23-49.

21. Klamen DL, Williams R, Hingle S. getting real: aligning the learning needs of clerkship students with the current clinical environment. Acad Med. 2019;94(1):53-58.

22. Lee Klamen D. Getting real: embracing the conditions of the third-year clerkship and reimagining the curriculum to enable deliberate practice. Acad Med. 2015;90(10):
1314-1317.

23. Han H, Roberts NK, Korte R. Learning in the real place: medical students' learning and socialization in clerkships at one medical school. Acad Med. 2015;90(2):231-239.

24. Hofmann H, Harding C, Youm J, Wiechmann W. Virtual bedside teaching rounds with patients with COVID-19. Med Educ. 2020 May 13 [Epub]. https:// doi.org/10.1111/medu. 14223.

25. Yuan J, Kim C. Guidelines for facilitating the development of learning communities in online courses. J Comput Assist Learn. 2014;30(3):220-232.

26. Lee SM. The relationships between higher order thinking skills, cognitive density, and social presence in online learning. Internet High Educ. 2014;21:41-52. 